\title{
Directory Management System: the Path Choice for Regulation of Electric Bicycle
}

\author{
Manman Zhou \\ Law School \\ Sichuan University \\ Chengdu, China
}

\begin{abstract}
With the rapid development of electric bicycle, its disadvantages and advantages have gradually appeared that has brought the wide argument on prohibition and restriction. As a normative governance model beyond the prohibition and restriction, the directory management system has more attention in the field of electric bicycle, because it has the basis of constitution and law and accords with the rule of law. Through the inspection on detailed methods of the directory management for electric bicycle in various areas, this paper puts forward concrete suggestions on the improvement of national directory management of electric bicycle from the three aspects of subject setting, effects and responsibilities.
\end{abstract}

Keywords-electric bicycle; directory management; subject setting; effects; responsibilities

\section{INTRODUCTION}

In April of this year, the traffic polices in Shenzhen detained 18 thousand electric vehicles within 10 days which brought the broad attention and query from the society. This again raised the argument on whether the electric bicycles should be "restricted" or "prohibited" which has lasted for years. The urban roads are becoming increasingly congested and the motor vehicle exhaust is becoming more and more severe, and under this case, the electric bicycles have rapidly become the important choice for the travel of people due to its advantages of environmental protection, convenience, fashion and cheapness. The reason why "Forbidding Order on Electric Bicycle" suffers great disputes and query is that it is difficult for the electric bicycle to pass the door of laws, namely some issues is worth of discussion both on the legislative authority and the legitimacy of the regulations. Therefore, currently, except for Guangzhou and a few of cities, all the cities adopt the regulation method of restriction for the electric bicycle. This change "means that the implementation departments start to abandon the 'forbidding instead of control' and adopt more pragmatic approach to deal with the existing key problems in the management and seek for fine and humanized governance methods"[1]. In the detailed regulation implementation, each city gradually finds the method to formulate the directory of electric bicycle for the source governance and further realizes the regulation objective of "prevention first, harmonious development". This paper is intended to inspect the current local norms and put forward the detailed countermeasures from the four aspects of subjects, efficacy, procedures and responsibilities.

\section{LEGAL GROUND FOR THE DIRECTORY MANAGEMENT SYSTEM OF ELECTRIC BICYCLE}

Essentially speaking, the complete prohibition or the restriction of electric bicycle will cause the restriction on the property rights of citizens. Therefore, its legal ground not only includes the higher-level law of road safety, but also the laws on reasonable restriction of citizen property rights implementation.

\section{A. Constitutional Grounds of Directory Management System}

Except that the classical natural laws stipulates the inviolability of private property, other thoughts and almost all the legislations permit the reasonable restriction on the private property of citizens. The academia has already done plenty of studies in this field. [2] However, with the private property listed into the constitutions, the restriction on private property must pass the constitutions. Nothing is more direct than the Paragraph 3 of Article 13 in our constitutions on the restriction of private property which stipulates that "for the needs of public interests, the state may conduct expropriation or requisition of citizens' private property and give them corresponding compensation according to stipulations in the laws", but it is hard to explain the "expropriation or requisition" is suitable for the directory management system of electric bicycle. The grounds provided by constitutions of China on the directory management system of electric bicycle lie in the following two aspects:

Firstly, Paragraph 2 of Article 1 in the constitutions states that "the socialist system is the basic system of the People's Republic of China and forbids any organizations or individuals destroying the socialist system". Naturally, the socialist system even emphasizes on the social equity and public interests. Therefore, the stipulations in this article exert the social duties essentially on the private property and thereby establish the restriction on private property. Indeed, the electric bicycle is the private property of the citizen however the electric bicycle must travel on the public roads and thereby should bear certain social duties. But this kind of duties is manifested through the restriction stipulations to a large extent and the directory management system is one of those aspects.

Secondly, Article 51 in the China constitutions states "when performing the freedom and rights, citizens in the People's Republic of China shall not damage the national, 
social and collective interests and the legal freedom and rights of other citizens". Currently, the most important reason why governments of various places forbid or restrict the electric bicycle lies in the poor safety and huge impacts on the transportation safety of electric bicycle. After facing the broad query, the event that Shenzhen Municipal Government put forward that the electric bicycle brings frequent traffic accidents is one of the evidences. Indeed, except for the advantages of environmental protection and convenience etc of electric bicycle, it also causes plenty of safe troubles due to its performance and other reasons. Therefore, to maintain the national, social and even others' legal interests, the normalized management must be conducted to the electric bicycle. The directory management system is the normalized management measure conducted from the source.

\section{B. Grounds of the Law on Road Traffic Safety of Directory Management System}

The constitutional grounds are more like a kind of concept, while the Law on Road Traffic Safety provides more direct legal grounds for the formulation of directory management system of various local governments. Paragraph 2 of Article 19 in the Law on Road Traffic Safety stipulates "the varieties of non-motor vehicles which shall be legally registered shall be stipulated by the People's Government of provinces, municipalities and municipalities directly under the Central Government according to the local practical truth". Although the stipulations in this Paragraph aim at the registration of nonmotor vehicles, governments of various places take the accordance with directory management as the precondition of registration and thereby formulate the directory management system based on the stipulations in this Paragraph.

\section{Other Grounds of Directory Management System}

The China constitutions and the Law on Road Traffic Safety provide legality for the formulation of directory management system while the relevant stipulations of the State Council provide more clear grounds on the aspects of subjects etc for the directory management system of electric bicycle. Article 12 in the Opinions of the State Council on Strengthening the Road Traffic Safety specifically stipulates the issue of security supervision of electric bicycle and clears the segregation of duties of relevant executive branches: provincial governments formulate the management methods; quality supervision departments take charge of the production permit and standard modification; Ministry of Industry and Information takes charge of the industrial management; administration for industry and commerce takes charge of the routine supervision of sales and the public security departments take charge of the traffic order and the investigating of traffic violations. The stipulations of the State Council are the most direct grounds for the formulation of directory management system of electric bicycle of local governments. And the department division is manifested in the stipulations of various local governments but there are slight differences in the details.

From the legal grounds of the directory management system of electric bicycle- also the legal grounds for of electric bicycle- we can see that it is unquestionable that the complete prohibition of electric bicycle has no legality grounds. Firstly, the complete prohibition of electric bicycle is the deprivation of the property rights of citizens, on one hand, this action can't be stipulated in the local normative documents, on the other hand, the complete prohibition of electric bicycle is not in accordance with the "validity" and "necessity" in the proportionality principles. Secondly, whether the Law on Road Traffic Safety or the Opinions of the State Council on Strengthening the Road Traffic Safety just grant the permission to the provincial governments for the formulation of management methods which means that on one hand, strictly speaking, they fail to grant the permission for complete prohibition, on the other hand, although they grant the provincial governments with the permission for prohibition, in the reality, the actions where the public security departments decide to prohibit are also illegal. Therefore, the directory management system of electric bicycle is the appropriate measure in accordance with the legal concepts and stipulations.

\section{SUBJECTS SETTING OF THE DiRECTORY OF ElECTRIC} BICYCLE

The directory management system of electric bicycle involves the tripartite subjects of setting subjects, manufacturing and sales companies and users which is related to the relations among the country, market and society form a certain perspective. Although the country, market and society are in the relations of mutual advancement and mutual promotion, China has always been with the deep governmentleading color while the occurrence of various reforms and new systems, to a great extent, belong to the constructivism and initiative decentralization of the governments, and "the system reform is the process of subject division, especially the division of administrative subjects". [3]Therefore, the setting subject of directory has significant meanings for the construction of directory management system of electric bicycle. The setting subjects of the directory management system of electric bicycle include the three subjects with close relations: management organizations, formulation subject and public participation, among which, the formulating subject involves the single directory system or double directory system.

\section{A. Management Organization: Unified Coordination Or Respectively Performing Its Own Functions?}

The directory management system of electric bicycle is one part of the management system of electric bicycle and most places have not specially formulated the directory management methods of electric bicycle but just stipulated in the management methods of electric bicycle therefore, the management organization of electric bicycle is the most important setting subject for the directory of electric bicycle. We can see from the Opinions of the State Council on Strengthening the Road Traffic Safety that the directory management system of electric bicycle involves multiple subjects: quality testing, Industry and commerce, industry and information and environmental protection etc. To coordinate those subjects, various places adopt different management methods.

To coordinate multiple departments, part places specially establish the management groups of electric bicycle or the 
unified coordination organizations such as the management companies. Those organizations are generally defined as conducting the management of electric bicycle under the leadership of the party committees and governments. Therefore, under the management mode of unified coordination, the directory of electric bicycle is usually one of the most important responsibilities of the unified organizations. Although the directory is formulated by the departments of quality testing, industry and commerce and the industry and information etc in details for the most part, basically speaking, the organizations with unified coordination are its setting subjects. The responsible persons of management organizations under unified coordination are almost the chiefs of the local public security bureaus.

Another part of places have not established the organizations under unified coordination but adopted the mode of "under the unified leadership of the party committees and governments, each department performs its own functions". Due to no unified organizations, to avoid the problems of divided policies from various sources and the different coordination, this mode adopts the local regulations or the normative documents to define the responsibilities of each department and require the leading departments to confer with other departments when formulating the directory of electric bicycle in details at the same time.

Although the organizations under unified coordination can avoid the divided policies from various sources and further solve the coordination problems among multiple departments, there still exists the following problems in organizations under unified coordination: firstly, organizations under unified coordination are mostly the temporary organizations and the personnel are all on part time which will greatly reduce the advantages; secondly, the independently external exercising the powers of organizations under unified coordination exists the obstacles by law on their own; thirdly, due the reason why practically the responsible persons of public security department are with higher ranks-is that they usually hold additional posts of the deputies in government or standing committee members in the party committees, them holding the additional posts of the responsible persons in the organizations under unified coordination will easily lead the directory management system of electric bicycle to the single traffic control but ignore the protection of citizen property rights and the development of the electric bicycle industry.

Therefore, the leading organ of directory management system of electric bicycle (management of electric bicycle) shall adopt the mode of "each department performs its own functions with cooperation under the unified leadership of the party committees and the governments". More specifically, establish the specific working mechanism and replace the unified organizations with the legalized (laws in broad sense) mechanism in the mode of local regulations and normative documents, based on the defining of responsibilities of the departments including quality testing, industry and commerce and industry and information and environmental protection.

\section{B. Formulating the Subjects}

The formulating subjects of directory of electric bicycle involve problems of two aspects: whether the directory of electric bicycle is unified directory or dispersed directory and which department shall formulate it in details.

1) Unified or dispersed: The directory of electric bicycle at least involves the directory of two aspects: directory of manufacturers and directory of produced products. The first one is the market access issues of company in narrow sense while the second is the market access issues in broad sense. It is exactly because the electric bicycle involves the directories of two aspects, in practice, the formulation of the two directories has divergences. Some places respectively formulate the "directory of manufacturers of electric bicycle" and the "directory of the product record of electric bicycle": which stipulate that only the electric bicycle products with listed in the directory of product record manufactured by the companies in the directory of the manufacturers of electric bicycle can be sold. Currently, only Chongqing has adopted the dispersed directory management system while other places all adopt the unified directory which defines the companies by products.

The respective formulation of "directory of manufacturers of electric bicycle" and the "directory of the product record of electric bicycle" seems to not only include the access of manufacturers but also include the operation access of companies and seems to be the relatively reasonable system. However, the directory of manufacturers of electric bicycle is definitely subject to the product directory of electric bicycle, that is, the determination of product directory of electric bicycle means the determination of the directory of manufacturers of electric bicycle. The dispersive stipulation increases the burden of related companies and the consumers which is not in accordance with the principle of administrative convenience for the people and will easily cause the situation of divided policies from various sources. Therefore, the directory of electric bicycle shall adopt the single directory mode defining companies by products.

2) Specific formulating department: Except that several places formulate the directory by single department, other places all require the leading department to confer with other departments to formulate the directory of electric bicycle together. However, there still exists a divergence on which organ shall be the leading organ to specifically take charge of the formulation in the practice. There are mainly four modes as follow: quality testing orientated, industry and commerce orientated, industry and information orientated and public security orientated, among which there are few situations taking public security department as the leading department and the first three situations are major modes.

Behind the different leading departments are the different attitudes toward electric bicycle. The quality testing department focuses on the quality of electric bicycle; the industry and commerce department focuses on the market supervision; the industry and information department focuses on the industry and standards while the public security department focuses on the traffic safety. We should say that the modes of various leading departments can make certain 
sense, however, the quality testing orientated seems to better comply with the law stipulations and more convenient for the settlement of the relations among the state, market and society. Firstly, the former paper discusses that the directory management system of electric bicycle is essentially the market access system, thus the directory management system of electric bicycle shall be linked up with the licensing system while the production license is issued by the quality testing department ; secondly, the quality testing evaluates the directory of electric bicycle which not only conforms to the purpose of traffic safety but also will not cause too much interference to the manufacturing and sales companies and the citizens.

\section{Public Participation}

The theory and system of public participation originate in the western democratic practice. "With the accelerating of integration process of the world economy, rapid development of information technologies and the gradual promotion of trend of administration democratization, public participation has become the worldwide trend of the development of modern public administration"[4]. Some scholars think that "as a kind of the institutionalized democratic systems, the public participation shall refer to the various behaviors where when the public power conducts legislation, formulates the public policies, decides the public affairs or conducts public governance, the public authorities shall obtain information, conduct hearing through open approaches and exert influence on public policies and governance behaviors through feedback and interaction"[5]. For the value of public participation, some scholars think that "in the modern society, exerting efforts to expand the approaches of public participation and trying hard to develop the participatory democracy are not only good for solving ... the practical problems but also may explore the approaches for the long-term goals of human political civilization"[6].

The public participation in the directory management system of electric bicycle can be divided into the mode of initiative actions of government with public participation and the mode of other organizations applying to participate, among which applying participation is in the majority and most of the situations of initiative actions of government with public participation are "can do" not "should do". The directory management system of electric bicycle is the important measure to restrict the citizen property rights which concerns to the vital interests of citizens. Therefore, the formulation process of directory management system of electric bicycle shall take the mode of government initiative conducting hearing to conduct the public participation and this mode is "should do" but not "can do".

\section{EFFECTS OF THE DIRECTORY OF ELECTRIC BICYCLES}

The directory management system of electric bicycle is stipulated in the normative documents of government and some of the system is even the contents in the provincial regulations. These normative documents belong to the range of generalized laws. The effects of law "refer to the constraint force and enforcement force, that is, all the laws legislated and enforced by the state have the constraint force and enforcement force on the universal laws" [7](p143). Therefore, the effects of the directory of electric bicycle also is the constraint force and enforcement force to the manufacturing and sales companies of electric bicycle and the citizens using the electric bicycle which mainly shows in the manufacturing and sales, registration and transitional schemes.

\section{A. Effects of Manufacturing and Sales}

The directory management system of electric bicycle requires the electric bicycles manufactured and sold must be the products already listed on the directory and the companies shall not manufacture the products not on the directory and the sales companies shall not sell the products not on the directory. And the system requires the sales companies to inform related stipulations in the directory management system. All those are the proper meanings of directory management system of electric bicycle. The most obvious effects of this system on the manufacturing and sales companies are to require the companies to conduct the declaration of products and only the products passing the declaration and being listed in the electric bicycle directory can be produced.

First is the declaration objective. Currently, almost all places require the manufacturing and sales companies to conduct the declaration with the reason that the products sold by sales companies may come from other places and may not be on the directory of manufactured products. For the principle of convenience for the people, the sales companies can conduct declaration by themselves or entrust other sales companies to conduct the declaration.

Second is the review subject. Most of the practices of each place are to conduct review to the declaration materials one by one. Of course, all places adopt the mode of handing over by the administrative organs themselves for the convenience of people. To manifest the thoughts of administrative convenience of people, efficient principle and rule-based governance, the review shall be conducted by one department. Because the directory management of electric bicycle is mainly to normalize the quality and the formulation of directory management of electric bicycle is dominated by the quality supervision department, the declaration shall be reviewed by this department and when necessary, the quality supervision department can confer with the industry and commerce department, industry and information department and the public security department. Due to the involving of following production, sales and registration etc, the results of review shall be jointly issued by the three departments.

What's more are the alteration and revocation. Except for the production of new products, the companies may be involved in the upgrading of technical standards and the obsolescence of original products and other situations. The upgrading of technical standards usually brings the alteration of coordination and parameters. For this kind of situations, the applications must be proposed to be altered; the products no longer being produced also need to apply for revocation.

\section{B. Registration for Riding on the Roads}

If we say the effects of production and sales are to settle the relations between the state and companies, then the 
registration for hitting the road is the effects on citizens and citizen property. To conduct effective management on the traffic safety of electric bicycle, most places conduct the realname registration system to the electric bicycle and only those pass the real-name registration system can hit the road. At the same time, whether conforming to the directory of electric bicycle is the necessary condition for the registration.

To save the costs for obtaining social information and for the disadvantaged consumers on the information comparing with the sales companies, we can learn the "sales with number plate of vehicles" of current vehicles in the sales of electric bicycle and conduct the "sales with number plate" system of electric bicycle- the sales companies directly manage the registration for consumers.

\section{Transitional Schemes}

The transitional schemes are mainly used to solve the settlement problems for the purchased electric bicycles not conforming to the directory management system of electric bicycle before the implementation of this system. For this, some people advocate the sweeping approach and think that only in this way can realize the purposes of directory management system to the greatest extent and maintain the authority and effects of the system. However, this solution is not in accordance with the legal ideas. First is that "in term of the time validity of laws, its general principles shall be no retrospective effects"; the second is that the so-called maintenance of the authority and effects of system will greatly reduce the authority and effects of the system because of the social acceptance level on the contrary. Therefore, the electric bicycle exceeding the standards purchased before the issuance of directory management system shall not be forbidden by sweeping approach while the scheme for transition period shall be formulated to solve this problem which specifically includes the following aspects:

The first is the orientation of electric bicycle exceeding standards. For the safety, the electric bicycles exceeding standards shall be taken into the management of motor vehicles which is because on one hand most of the electric bicycles exceeding standards are with excessively fast speed and too strong power etc and on the other hand the Technical Conditions for Motor Vehicles Safety also can provide the legal ground. This requires that when driving the electric bicycles exceeding standards people must wear crash helmets; drive along the most right side of motor ways; purchase the compulsive car insurances etc.

The second is the management of temporary traffic permits. Because the electric bicycles exceeding the standards cannot manage the registration of electric bicycles, they are required to manage the temporary traffic permits within ninety days after the issuance of the directory management of electric bicycle.

The third is the transitional time. Currently, each place has different start counting and length of the transitional time. Some places take the purchasing as the start counting point and take the five years after the date of purchasing as the transitional period; some places take the issuing date of directory management system as the start counting point within three years or five years for some places; there are also some places taking the management date of temporary traffic permit as start counting point and taking five years as the transitional period. Taking the management date of the issuance of directory management system and the temporary traffic permit as start counting point can't grasp the depreciation conditions of electric bicycle which is bad for the traffic safety. Therefore, the transitional time shall take the purchasing date of electric bicycles and take the five years after purchasing as transitional period.

The fourth is to encourage the "trading new good for old" and "trade-in buy-back". That is to encourage the companies to conduct the technical transformation to the vehicles exceeding standards purchased before the directory management system through "trading new good for old" and "trade-in buy-back" and other measures so as to make it meet the requirements of the directory management system of electric.

\section{RESPONSIBILITIES FOR THE DIRECTORY OF ELECTRIC BICYCLES}

"As the safeguard mechanism for legal operation, the legal responsibilities are the indispensable link for rule of law" [8](p116). In this sense, the responsibility system of the directory of electric bicycle concerns the implementation effects of the directory system of electric bicycle. The responsibility system in the directory of electric bicycle mainly involves four aspects: the manufacturers violating responsibilities in the directory management system; sales companies violating responsibilities in the directory management system; consumers violating responsibilities in the directory management system; civil servants violating responsibilities in the directory management system.

\section{A. Responsibilities of Manufacturers for Violation of the Directory Management System}

The manufacturers of electric bicycle must formulate the safeguard scheme for the production conformity to conduct the production according to the national technical standards and production parameters stipulated in the directory and to require the sales companies not to alter the technical labels and parameters by signing protocols and other measures. If the department of directory management finds the manufacturers manufacture the products not listed in the directory or not in accordance with the directory management, the department shall immediately require the manufacturers to stop manufacturing and even delete the companies from the product directory of electric bicycle in the serious conditions. For the products already accessed to the market but not in accordance with the standards, the department shall require the company to recall the products with a time limit. At the same time, if the manufacturing not in accordance with the directory management, the products will not meet the quality requirement in the directory, and the department shall deal with it according to the Quality Law of the People's Republic of China. 


\section{B. Responsibilities for Sales Companies on Violation of the Directory Management System}

Firstly, in the case where the sales companies sell the products not listed in the directory or not in accordance with the directory management, the companies shall be required to stop the sales and the matters will be submitted to the institutions of industry and commerce and quality supervision for settlement according to laws and regulations, and if the case is serious, the business license of the company shall be revoked.

Secondly, in the case where the consumers can't apply for the registration of electric bicycles because the sales companies sell the products not listed in the directory on or not in accordance with the directory management, the consumers may require the company to exchange goods or refund and also ask for compensation according to the relevant stipulations in the Law of the PRC on the Protection of the Rights and Interests of Consumers.

\section{Responsibilities for the Consumers on Violation of the Directory Management System}

The violation of directory management system for consumers mainly means that after the issuance of directory management system, consumers purchase the electric bicycles not listed in the directory or not in accordance with the directory management, the electric bicycles without legal sources or the illegally-refit electric bicycles. In those cases, the relevant department may not grant registration and not allow them riding on the road.

\section{Responsibilities of Civil Servants for Violation of the \\ Directory Management System}

The principle of administrative law is to restrict the governmental power to safeguard the legal rights of citizens. Therefore, the investigation on the responsibilities of illegal civil servants in the administration seems more important. For the management organizations of directory of electric bicycle, whether it is the quality testing institution, industry and commerce, industry and information or the public security department, in the case of misuse of authority, fraudulent practices or misconduct in office, the institution, supervisory organs or the higher organs of the civil servants shall give instruction for correction and administrative punishment; if the case is serious, the directly relative principal or other principal will accept disciplinary sanctions; if the case constitutes a crime, the relative responsible person will accept criminal sanctions according to laws.

\section{Conclusion}

As a new regulation mode beyond the traditional argument on prohibition and restriction, the directory management system of electric bicycle effectively coordinates the relations among the state, market and society in the field of electric bicycle and has achieved great effects in various places. The development tendency of directory management of electric bicycles in the future should be to achieve the purpose of good governance by defining the functions, advocating public participation and fulfilling responsibilities based on the coordination of citizen property implementation and the social public interests.

\section{REFERENCES}

[1] Shi Lidong, Yu Lingyun. Governance of Electric bicycle [J] Zhejiang Academic Journal, 2015, (2).

[2] Wang Haiyan. Study on the Restriction of Private Property [J] Journal of Hubei University of Education, 2014, (12).

[3] Zhang Shuyi. Study on Administrative Subject [J] CHINESE LEGAL SCIENCE, 2000, (2).

[4] Jiang Bixin. Challenges on Administrative Law and Administrative Jurisprudence from the Tendency o Public Participation [J] CHINESE LEGAL SCIENCE, 2006, (6).

[5] Cai Dingjian. Public Participation and the Development in China [J] Unity, 2009, (4).

[6] Jiang Mingan. Public Participation and Rule of Administrative Law [J] CHINESE LEGAL SCIENCE, 2004, (2).

[7] Zhang Wenxian. Jurisprudence (Edition III) [M] Beijing: Law Press China, 2007.

[8] Zhang Wenxian. Study on Law Philosophy Category (Revised Edition) [M] Beijing: China University of Political Science And Law Press, 2003 